\title{
A dignidade humana enquanto princípio de proteção e garantia dos direitos fundamentais sociais: 0 direito à saúde
}

Human dignity as a principle for the protection and guarantee of social fundamental rights: the right to health

La dignidad humana como principio de la protección y los derechos fundamentales garantizados social: el derecho a la salud

Sandra Regina Martini ${ }^{1}$ Janaína Machado Sturza²

RESUMO: Objetivo: explorar o princípio da dignidade humana como instrumento de subsídio para a consecução do direito à saúde. Metodologia: realizou-se estudo bibliográfico, tendo como método de abordagem o hipotético-dedutivo. Resultado: a Constituição de 1988 plasmou a dignidade da pessoa humana como instrumento de subsídio para a consecução do direito à saúde, retratando o reconhecimento de que o indivíduo há de constituir o objetivo primordial da ordem jurídica. Conclusão: verificou-se que a saúde se constituiu como um direito reconhecido igualmente a todo o povo, consolidando-se como meio de preservação da vida.

Palavras-chave: Direito à saúde. Direito Constitucional. Justiça social.

ABSTRACT: Objective: the principle of the dignity of the human person is constitutionally guaranteed in Brazil and its realization leads to the guarantee of several other rights, among which health. Methods: Based on this scenario, the present text aims to promote the discussion about the theme of fundamental social rights, especially on the guarantee and effectiveness of the right to health from the point of view of the principle of human dignity. Results: through a bibliographical study, taking as hypothetic-deductive method of approach. Conclusion: it was verified that health was constituted as a right recognized equally to all the people, consolidating itself as a means of preserving life.

Keywords:. Right to health. Constitutional Law. Social justice.

RESUMEN: Objetive: el principio de la dignidad humana está garantizada constitucionalmente en Brasil y su realización lleva a garantizar una serie de otros derechos, entre los cuales la salud. Metodologia: A partir de este escenario, el presente trabajo tiene como objetivo estimular el debate sobre el tema de los derechos sociales

\footnotetext{
1 Professora Produtividade CNPq, Pós doutora em Direito (Univerisità Roma Tre), Pós Doutora em Políticas Públicas (Università Salerno), Doutora em Direito (Università do Salento). Professora Visitante no PPGDIR/UFRGS e Professora no Mestrado em Direitos Humanos da Universidade Ritter dos Reis - UNIRITTER. Porto Alegre/RS - Brasil. Email: srmvial@terra.com.br

2 Doutora em Direito (Univerisità Roma Tre), Mestre em Direito (UNISC) e Especialista em Demandas Sociais e Políticas Públicas (UNISC). Professora na graduação em Direito da Faculdade Dom Alberto. Professora na graduação em Direito e no Mestrado em Direitos Humanos da Universidade Regional do Noroeste do Estado do Rio Grande do Sul - UNIJUI. ljuí/RS - Brasil. Email: janasturza@hotmail.com
} 
fundamentales, en particular sobre la seguridad y la garantía del derecho a la salud desde la perspectiva del principio de la dignidad humana. Resultados: a través de un estudio bibliográfico, con el método hipotético-deductivo de enfoque. Conclusión: se encontró que la salud se constituye como un derecho reconocido también a todas las personas, consolidando su posición como un medio para preservar la vida.

Palabras clave: Derecho a la salud. Derecho Constitucional. Justicia social.

\section{Considerações iniciais}

O presente artigo tem como interesse principal a exploração acerca da temática que envolve o princípio da dignidade humana enquanto instrumento de subsídio para a consecução do direito à saúde, vislumbrando-se, neste contexto, uma tentativa de articular e elaborar ações em direção ao exercício efetivo da cidadania, permitindo à sociedade reduzir os excessos de desigualdade e garantindo o bem-estar a todos, ressaltando, primordialmente, a ideia de justiça social.

A partir deste ideário, o texto tem como objetivo fomentar a reflexão acerca do direito à saúde, especificamente no que tange à sua proteção e garantia sob o ponto de vista do princípio constitucional da dignidade humana. Nessa perspectiva, nada mais adequado que a utilização dos pressupostos constitucionais contemporâneos, verificando-se, através de uma abordagem doutrinária que segue o método hipotético dedutivo, possibilidades jurídicas de contextualizar e analisar o direito à saúde.

Assim, o Direito à Saúde no Brasil, como aponta a nossa Constituição Federal de 1988, é um direito de todos e um dever do Estado, calcado no art. 196 da Constituição e garantido mediante políticas sociais e econômicas que visam à redução do risco de doença e de outros agravos e ao acesso universal e igualitário às ações e serviços para sua promoção, proteção e recuperação. Através deste dispositivo legal o termo saúde se constituiu como um direito reconhecido igualmente a todo o povo, além de ser um meio de preservação e de qualidade de vida, emergindo, nesse sentido, como um fator de contribuição para o efetivo exercício da cidadania.

Desta forma, a saúde representa uma preocupação constante na vida de cada cidadão, enquanto elemento fundamental para as necessidades de segurança em vários aspectos do bem viver em comunidade. A complexidade dos aparatos necessários para dar uma resposta a tal preocupação é acrescida com a articulação dos Estados Modernos, muitas vezes de forma desviante em relação ao objetivo originário. A solução para o acesso igualitário ao Direito à Saúde, em parte, é atribuída a setores da política econômica 
e social do país, aliando a isto o esforço conjunto de toda a coletividade representada pela sociedade.

Hoje, na sociedade contemporânea, a saúde é indiscutivelmente um direito fundamental, além de ser também um importante investimento social. Na medida em que os governos têm o objetivo de melhorar as condições de saúde de todos os cidadãos, é necessário que invistam recursos em políticas públicas de saúde, capazes de garantirem programas efetivos para a sua promoção. Todavia, garantir o acesso igualitário a condições de vida saudável e satisfatória a cada ser humano constitui um princípio fundamental de justiça social e, portanto, exige também uma grande produtividade complexa por parte da sociedade e do Estado, sendo necessária a intensificação dos esforços para coordenar as intervenções econômicas, sociais e sanitárias através de uma ação integrada.

Neste sentido o texto constitucional diz que a dignidade da pessoa humana é fundamento da República Federativa do Brasil, concluindo-se a partir disso que o Estado existe em função de todas as pessoas e não estas em função do Estado. Assim, toda e qualquer ação do ente estatal deve ser avaliada, sob pena de inconstitucional e de violar a dignidade da pessoa humana. Ela é, assim, paradigma avaliativo de cada ação do Poder Público e um dos elementos imprescindíveis de atuação do Estado brasileiro.

Por conseguinte, para o pleno desenvolvimento de cada pessoa, enquanto membro ativo de uma sociedade democrática e igualitária, são exigidos não somente a garantia do acesso universal ao Direito à Saúde, mas também o seu efetivo cumprimento e satisfação, através da ativa intervenção de um Estado calcado na dignidade da pessoa humana, buscando remover obstáculos e promover a saúde para todos os seus cidadãos, pois Direito à Saúde é direito à vida, o bem máximo de cada ser humano enquanto membro de um Estado Democrático de Direito que tem (ou deveria ter) como escopo o efetivo exercício da cidadania.

\section{Dos primórdios a contemporaneidade: o conceito de saúde}

$\mathrm{Na}$ sociedade contemporânea, a saúde deve ser considerada como um bem de todos, como um direito social necessário à manutenção da vida. Entretanto, o reconhecimento de sua eficácia é um forte argumento colocado em discussão nos dias atuais, principalmente em relação aos "direitos sociais e as externalidades que não podem 
ser internalizadas na avaliação da saúde enquanto bem econômico" (1). Neste sentido, ainda pode-se destacar que nos Estados Novos e mesmo nos reformados e nas sociedades mais desenvolvidas e tradicionais, destaca-se um grandioso interesse no tratamento da saúde enquanto direito (2). Nesta abordagem, destacam-se as seguintes palavras:

La salute costituisce ormai da tempo uno dei temi più ampiamente discussi dagli studiosi delle scienze giuridiche e sociali, trovandosi contemporaneamente sempre al centro del dibattito istituzionale tra mutevoli orientamenti politico-ideologici nei confronti dello stato sociale ${ }^{3}(3)$.

Assim, o primeiro conceito de saúde provavelmente foi externado pelos pensadores da Grécia Antiga, através do brocardo "Mens Sana In Corpore Sano", constituindo-se como um marco na definição de saúde. A partir do século XX, com o surgimento da Organização Mundial de Saúde (OMS) em 1946, a saúde foi definida como o completo bem-estar físico, mental e social e não somente a ausência de doenças ou agravos, sendo reconhecida como um dos direitos fundamentais de todo ser humano, seja qual for sua condição social ou econômica e sua crença religiosa ou política ${ }^{4}$.

Diante disto, a saúde surge como uma incessante busca pelo equilíbrio entre influências ambientais, modos de vida e outros tantos componentes. Neste sentido, em uma visão bastante avançada para a sua época de construção, a OMS expandiu o conceito de saúde historicamente atrelado à cura e abarcando, essencialmente, a promoção da saúde.

Todavia, a chegada do século XX impulsionou marcantes transformações sociais, juntamente com as grandes guerras ocorridas no mesmo período. Até então a saúde era vista como algo individual, passando a ter outra conotação com a chegada da ideia do Welfare State, surgida após estas grandes guerras e trazendo consigo a visão do Estado de Bem-Estar Social, caracterizando-se como um marco nas ideias de saúde enquanto prevenção:

A prevenção complexifica o tema incorporando ao mesmo uma situação antecipada no sentido de evitar a ocorrência da doença através de serviços básicos garantidores da salubridade pública. Percebe-se, então, que a saúde não se restringe mais à busca individual e passa a ter uma feição

\footnotetext{
3"A saúde constitui-se já há tempo um dos temas mais amplamente discutidos pelos estudiosos das ciências jurídicas e sociais, encontrando-se contemporaneamente sempre ao centro dos debates institucionais entre as mutáveis orientações político-ideológicas nos confrontos do estado social." Tradução Livre.

${ }^{4}$ Disponível em: <http://jus2.uol.com.br/doutrina/texto.asp?id=4839\&p=2>. Acesso em julho 2016.
} 
coletiva na medida em que a saúde pública passa a ser apropriada pelas coletividades como direito social, como direito coletivo, bem como alarga-se o seu conteúdo. Tem-se a prevenção da doença (4).

Finalmente adentra-se no século XXI, auge da expansão dos meios de comunicação e em especial da informática. Vive-se um momento em que a criatividade humana alcançou uma extraordinária expressividade, colocando-se em um novo sistema de alcance global. Este século herdou fantásticas experiências científicas e tecnológicas, que promoveram o crescimento da produção e proporcionaram condições de bem-estar e de acesso a serviços, como nos setores da saúde.

Por conseguinte, o entendimento de saúde passa por vários períodos da história da humanidade, alcançando em alguns momentos o status curativo e em outros o status preventivo. Todavia, a base para ambas as visões é a ideia de saúde enquanto ausência de doenças, sendo esta abordagem modificada com a chegada do conceito trazido pela OMS5, no qual é evidenciado a importância da existência de uma qualidade para o equilíbrio interno do homem com o meio ambiente.

Ainda sobre o conceito de saúde acordado pela OMS, tem-se que este corresponde à definição de felicidade e que tal estado de completo bem-estar é impossível de ser alcançado, posto que não é nada operacional. Muito embora este conceito tenha grande aceitação, ele é marcado por um caráter positivo e outro negativo. O primeiro trata da promoção do bem-estar e o segundo da ausência de enfermidade. Para complementar o exposto, merecem destaque as seguintes palavras:

[...] é apresentado o conceito de saúde adotado: "Saúde é o completo bemestar físico, mental e social e não apenas a ausência de doenças ou outros agravos." Observa-se portanto, o reconhecimento da essencialidade do equilíbrio interno e do homem com o ambiente (bem-estar físico, mental e social) para a conceituação da saúde, recuperando a experiência predominante na história da humanidade [...] (5).

A saúde, então, pode ser considerada também sob outros aspectos, tendo em vista que abrange toda a coletividade, inserida nos direitos sociais onde o ideal passa a ser a prevenção e não a cura estritamente. O conceito de saúde está relacionado à questão de o cidadão ter direito a uma vida saudável, que resultará em sua qualidade de vida, uma vez que "[...] dal diritto alla vita discende il diritto all'integrità física, che è una parte del diritto

\footnotetext{
"Saúde é o completo bem-estar físico, mental e social e não apenas a ausência de doenças ou outros agravos."
} 
alla salute. Esso consiste nel diritto di ogni uomo o donna a mantenere integro il próprio corpo $^{6}$ "(6). Assim, a promoção e proteção de uma qualidade de vida digna - aqui destacando-se a saúde - deve primar pelos benefícios para o desenvolvimento do homem e sua existência, constituindo-se como "o centro de irradiação por excelência de todos os bens ou interesses jurídicos protegidos" (7).

\section{A saúde como um direito fundamental social a partir da Constituição Federal de 1988}

O tema do Direito à Saúde não era de todo estranho ao nosso Direito Constitucional anterior a 1988, o qual delegava competência à União para legislar sobre defesa e proteção da saúde, sendo que isso tinha sentido de organização administrativa de combate às endemias e epidemias. Todavia, na atual conjuntura isto foi modificado, uma vez que na promulgação da Constituição Cidadã a saúde passou a ser um direito do homem (8), assumindo status de grande relevância em nosso ordenamento jurídico.

Em nosso país, portanto, a saúde foi realmente reconhecida como direito em 1988, com a promulgação da nossa Constituição Federal. Esta Carta proclama a existência do Direito à Saúde como um dos direitos fundamentais da pessoa humana, além de estabelecer a saúde como direito de todos e dever do Estado, organizando a forma e os aspectos do atendimento a ser dado através da criação de um Sistema Único de Saúde (art. 200) (9).

Desta forma, a evolução conduziu à concepção da nossa Constituição Federal de 1988, na qual em seu Art. 196 estabelece que "A saúde é direito de todos e dever do Estado, garantido mediante políticas sociais e econômicas que visem à redução do risco de doença e de outros agravos e ao acesso universal igualitário às ações e serviços para sua promoção, proteção e recuperação" (10).

Por conseguinte, no Brasil o acesso ao Direito à Saúde passou por grandes transformações e, a despeito de muitos obstáculos, opostos por setores sociais privilegiados e retrógrados, tem havido muitos avanços na luta pelo estabelecimento de melhores condições de vida para todos os brasileiros, dentre elas a saúde. Nesta área é possível perceber o evidente progresso, podendo-se considerar superada a concepção

6"O ordenamento Italiano tutela como direito primário, absoluto e inatingível o direito à vida. Do direito à vida descende o direito à integridade física, que é uma parte do direito à saúde. Esse consiste no direito de cada homem ou mulher a manter íntegro o próprio corpo." Tradução Livre. 
estreita e individualista que limitava a saúde exclusivamente ao oferecimento de serviços médico - hospitalares, dos quais somente os mais ricos teriam acesso, sendo que aos pobres restariam a precariedade e ainda como um favor do Estado (11).

Através do princípio de que o direito à saúde é igual à vida de todos os seres humanos, significa também que, nos casos de doença, cada um tem o direito a um tratamento condigno de acordo com o estado atual da ciência médica, independentemente de sua situação econômica, sob pena de não ter muito valor sua consignação em normas constitucionais (8).

O Direito à Saúde, a partir do artigo 196, utilizando-se do artigo 197, ambos da Carta Magna, retratam a relevância pública das ações e serviços de saúde, cabendo ao Poder Público dispor, nos termos da lei, sobre sua regulamentação, fiscalização e controle. Assim, sua execução deve ser feita diretamente ou então através de terceiros, ou ainda, por pessoa física ou jurídica de direito privado (12). Portanto, na conformidade do artigo 196, o Direito à Saúde, respaldado em tal dispositivo legal, trata-se de um programa a ser atendido pelo Estado, mediante norma de conteúdo programático, através da qual fixam-se vetores maiores que apontam para direções e objetivos a serem atingidos pela ação estatal (13). Nesse sentido:

No Brasil, os litígios em matéria de saúde que possuem mais evidência são aqueles em que o acesso é o objeto material da demanda. De um lado está o cidadão enfermo, demandando ações ou insumos de saúde contra o Estado provedor de serviços públicos de saúde, que por razões de ausência do serviço ou não previsibilidade do mesmo em políticas públicas o deixa de oferecer. Trata-se de um "enfrentamento social" que ganhou proporções epidêmicas e que os mecanismos clássicos de resolução dos conflitos acabaram por produzir externalidades negativas para o Sistema Único de Saúde, já debilitado por razões diversas (14).

Sendo assim, o Direito à Saúde trata de um direito positivo, que exige prestações do Estado e que impõe aos entes públicos a realização de determinadas tarefas, de cujo cumprimento depende a própria realização do direito (8). Nesta esfera decorre um especial direito subjetivo de conteúdo duplo, por um lado, pelo não cumprimento das tarefas estatais para sua efetivação, dá cabimento à ação de inconstitucionalidade por omissão (arts. 102 , I, a e $103, \S 2^{\circ}$ ) e, por outro lado, o seu não atendimento, inconcreto, por falta 
de regulamentação, pode abrir pressupostos para a impetração do mandado de injunção (art. 5ㅇ, LXXI).

A saúde, em nível constitucional e da legislação ordinária, é um bem jurídico tutelado, extensivo a todas as pessoas que estejam sujeitas à ordem jurídica brasileira. É, portanto, intolerável que uma pessoa ou toda a coletividade possa ser ferida nesse direito, sem que as leis brasileiras lhe deem a devida proteção (15).

É possível visualizar-se, desta forma, a consciência de cidadania expressa na Constituição, a qual elencou um rol quase exaustivo de direitos e garantias individuais, além, é claro, dos direitos sociais. É neste patamar que se encontra o Direito à Saúde, ou seja, um direito fundamental social de segunda geração (16). E, para ratificar tal exposição, pode-se citar Dallari, p. 32 (17), quando diz que "[...] o direito à saúde deve ser assegurado a todas as pessoas de maneira igual [...]."

Notadamente, este direito acena como um dos importantes elementos da cidadania, como um direito à promoção da vida das pessoas, pois Direito à Saúde é direito à vida (4). Partindo desta análise, a questão do Direito à Saúde é universal, assim como a do acesso igualitário às ações de saúde, estando assegurado constitucionalmente tanto na seção específica como nas disposições gerais sobre a Seguridade Social (18).

Portanto, nossa Constituição Federal indica já em seu preâmbulo a positivação de um Estado Democrático, destinado a assegurar o exercício dos direitos sociais e individuais, a liberdade, a segurança, o bem-estar, o desenvolvimento, a igualdade e a justiça como valores supremos de uma sociedade fraterna, pluralista e sem preconceitos, fundada na harmonia social e abrangendo, assim, o Direito à Saúde (19).

\section{O princípio da dignidade humana e o direito à saúde}

O ser humano é, sem dúvida alguma, o centro e o fim do Direito, sendo esta característica pautada no valor básico do Estado Democrático de Direito, que é a dignidade da pessoa humana. Hoje, na sociedade contemporânea, está se vivenciando um período onde o discurso jurídico, na maioria das vezes, não condiz com tudo aquilo que dele se poderia esperar, já que a prática não reflete o que propõe. Portanto, "[...] vivemos hoje numa sociedade paradoxal. A afirmação discursiva dos valores é tanto mais necessária quanto mais as práticas sociais dominantes tornam impossível a realização desses valores" (20). 
No mundo globalizado em que se vive, onde o poder econômico impera e dita as regras no seio da sociedade, a condição humana encontra-se constantemente submissa a todas as formas indignas de atitudes e comportamentos, daí que sempre aparecem manifestações favoráveis pelo reconhecimento da dignidade das pessoas submetidas a situações de aviltamento.

Por conseguinte, a Constituição de 1988 deixou claro que o Estado Democrático de Direito instituído tem como fundamento a dignidade da pessoa humana (art. 1ํㅡㄴ III) (Brasil, 1988) $)^{7}$, reconhecendo na dignidade pessoal a prerrogativa de todo ser humano em ser respeitado como pessoa, de não ser prejudicado em sua existência (a vida, o corpo e a saúde) e de fruir de um âmbito existencial próprio.

Assim, quando a Constituição Federal elencou a dignidade da pessoa humana como um dos princípios fundamentais da República, consagrou a obrigatoriedade da proteção máxima à pessoa por meio de um sistema jurídico-positivo formado por direitos fundamentais e da personalidade humana, garantindo assim o respeito absoluto ao indivíduo, propiciando-Ihe uma existência plenamente digna e protegida de qualquer espécie de ofensa, quer praticada pelo particular, como pelo Estado.

Portanto, o princípio da dignidade da pessoa humana como parâmetro valorativo evoca, primordialmente, o condão de impedir a degradação do homem, em decorrência de sua conversão em mero objeto de ação estatal, uma vez que compete ao Estado o dever de propiciar ao indivíduo a garantia de sua existência material mínima (21), ressaltando-se aqui a saúde essencialmente enquanto direito.

Neste sentido, a preocupação do homem com a sua saúde sempre foi uma constante como maneira de preservar a própria sobrevivência, sobretudo a vida, sendo inúmeros os progressos realizados à medida que a ciência avança e faz novas descobertas, diversificando as possibilidades de tratamento. Essa evolução cristalina das formas de tratamento de doenças e de preservação da saúde surgiu acompanhada da multiplicação dos seus custos, o que tornou impossível, em muitos países, o acesso da população em geral a essas evoluções tecnológicas. O próprio Estado, que surge como o responsável

\footnotetext{
7“Art. $1^{\circ}$ A República federativa do Brasil, formada pela união indissolúvel dos Estados e Municípios e do Distrito Federal, constitui-se em Estado Democrático de Direito e tem como fundamentos: [...]; III a dignidade da pessoa humana; [...]" BRASIL. Constituição (1988). Constituição da República Federativa do Brasil. Brasília, DF: Senado Federal, 1988.
} 
pela preservação desse acesso ao serviço de saúde, com o passar do tempo, revelou-se incompetente ou impotente para fazer frente aos seus elevados custos (22).

A consagração constitucional da dignidade da pessoa humana resulta, pois, na obrigação do Estado em garantir à pessoa humana um patamar mínimo de recursos, capaz de garantir-Ihes direitos básicos, como a saúde. O direito à existência digna não é assegurado apenas pela não abstenção do Estado em afetar a esfera patrimonial das pessoas sob a sua autoridade, mas passa também pelo cumprimento de prestações positivas.

Em nosso País, o direito à existência digna é refletido, entre outros aspectos, pela obrigação atribuída ao Estado e à sociedade de realização de ações integradas para a implementação da seguridade social, a qual é destinada, entre outras coisas, a assegurar a prestação dos direitos inerentes à saúde, onde estão incluídas as ações realizadas mediante políticas sociais e econômicas que tem por objetivo a redução dos riscos de doença e de outros agravos, garantindo desta forma o acesso universal e igualitário às ações e serviços para promoção, proteção e recuperação da saúde enquanto um bem imprescindível à vida (21).

Os preceitos da dignidade da pessoa humana se consolidam na medida em que são respeitados os direitos fundamentais e direitos da personalidade, o que importa afirmar que "a previsão dos direitos humanos fundamentais direciona-se basicamente para a proteção à dignidade humana em seu sentido mais amplo" (12). É importante destacar aqui a base da formação e existência dos direitos fundamentais, onde:

[...] o homem, para poder viver em companhia de outros homens, deve ceder parte de sua liberdade primitiva que possibilitará a vida em sociedade. Essas parcelas de liberdades individuais cedidas por seus membros, ao ingressar em uma sociedade, se unificam, transformando-se em poder, o qual é exercido por representantes do grupo (23).

Dessa forma o poder e a liberdade são fenômenos sociais contraditórios, que tendem a anular-se reciprocamente, merecendo por parte do direito uma regulamentação, de forma a impedir tanto a anarquia quanto a arbitrariedade. Nesta esfera, portanto, surge a Constituição Federal, que, além de organizar a forma de Estado e os poderes que exercerão as funções estatais, igualmente consagra os direitos fundamentais a serem 
exercidos pelos indivíduos, principalmente contra eventuais ilegalidades e arbitrariedades do próprio Estado (12).

Neste contexto, é possível constatar a relação direta entre dignidade da pessoa humana e direitos fundamentais, em especial aqui a saúde, sendo que mesmo nas ordens normativas nas quais a dignidade ainda não mereceu referência expressa, não se poderá concluir que não se faça presente, na condição de valor informador de toda a ordem jurídica, desde que nesta estejam assegurados os direitos fundamentais inerentes à pessoa humana. Com efeito, sendo correta a premissa de que os direitos fundamentais constituem explicitações da dignidade da pessoa, por via de consequência e, em princípio, em cada direito fundamental se faz presente um conteúdo ou alguma projeção da dignidade da pessoa (24).

A dignidade da pessoa humana, na condição de valor e princípio normativo fundamental atrai o conteúdo de todos os direitos fundamentais, exigindo e pressupondo 0 reconhecimento e a proteção dos direitos fundamentais de todas as dimensões (ou gerações). Desta forma, "sem que se reconheçam à pessoa humana os direitos fundamentais que lhe são inerentes, em verdade estar-se-á lhe negando a própria dignidade" (24).

Assim, por força dos elementos até este passo desenvolvidos, outra não poderia ser a conclusão quanto à impossibilidade de se dissociarem os vetores da dignidade da pessoa humana do direito à saúde e, consequentemente, da vida. Pode-se dizer, pois, que a previsão do direito à saúde e à vida como cláusulas pétreas e suas relações com o fundamento constitucional da dignidade da pessoa humana trazem, como consequência, a necessidade de o Poder Público assegurar a eficiente prestação dos serviços públicos necessários à garantia de uma condição de vida digna, sob pena de responsabilidade. Oportuno, então, dizer que o direito a saúde:

[...] representa consequência constitucional indissociável do direito a vida. O Poder Público, qualquer que seja a esfera institucional de sua atuação no plano da organização federativa brasileira, não pode mostrar-se indiferente ao problema da saúde da população sob pena de incidir, ainda que por censurável omissão, em grave comportamento inconstitucional ${ }^{8}$.

\footnotetext{
${ }^{8} \mathrm{AgRg}$ no RE n. 271.286-8/RS, rel. Min. Celso de Mello, J. Em 12.9.2000, Boletim de Direito Administrativo, ago. 2001, p.
} 641. 
No que tange especificamente à dignidade da pessoa humana, ainda pode-se destacar aqui quatro importantes consequências avistadas em nossa sociedade hodierna, sendo elas: igualdade de direitos entre todos os homens, uma vez que integram a sociedade como pessoas; garantia da independência e autonomia do ser humano, de forma a obstar toda coação externa ao desenvolvimento de sua personalidade, bem como toda atuação que implique na sua degradação; observância e proteção dos direitos inalienáveis do homem; inadmissibilidade da negativa dos meios fundamentais para o desenvolvimento de alguém como pessoa ou a imposição de condições subumanas de vida (21).

Portanto, a consagração da dignidade da pessoa humana implica em considerar o homem, com exclusão dos demais seres, como o centro do universo jurídico. Esse reconhecimento abrange todos os seres humanos e cada um destes individualmente considerados, de sorte que a projeção dos efeitos irradiados pela ordem jurídica não há de se manifestar, a princípio, de modo diverso ante a duas pessoas.

A partir desta abordagem seguem-se duas importantes consequências, a de que a igualdade entre os homens representa obrigação imposta aos poderes públicos, tanto no que concerne à elaboração da regra de direito como igualdade na lei, quanto em relação à sua aplicação como igualdade perante a lei. Necessária, porém, a advertência de que o reclamo de tratamento isonômico não exclui a possibilidade de discriminação, mas sim a de que esta se processe de maneira injustificada e desarrazoada, isso sem esquecer das considerações acerca do princípio da dignidade da pessoa humana como um conceito dotado de universalidade (21).

A proclamação do valor distinto da pessoa humana tem como consequência lógica a afirmação de direitos específicos de cada homem. A dignidade da pessoa humana é, por conseguinte, o núcleo essencial dos direitos fundamentais e a fonte ética, que confere unidade de sentido, de valor e de concordância prática ao sistema dos direitos fundamentais. Em consequência, na centralidade dos direitos fundamentais dentro do sistema constitucional, eles apresentam não apenas um caráter subjetivo, mas também cumprem funções estruturais enquanto condição sine qua non do Estado Democrático de Direito.

Sendo assim, este princípio da dignidade da pessoa humana assume posição de destaque, servindo inclusive como diretriz material para a identificação de direitos 
implícitos de cunho defensivo e prestacional e, de modo particular, abarcados em outras partes da Constituição Federal. Trata-se na verdade de critério basilar e não exclusivo, onde sempre que se puder detectar, mesmo para além de outros critérios que possam incidir na espécie, que se está diante de uma posição jurídica diretamente embasada e relacionada à proteção da dignidade da pessoa humana, inequivocamente estar-se-á diante de uma norma de direito fundamental (24).

O expresso reconhecimento da dignidade da pessoa humana como princípio fundamental apresenta, em parte, a pretensão constitucional de transformá-lo em um parâmetro objetivo de harmonização dos diversos dispositivos constitucionais, obrigando o intérprete a buscar uma concordância prática entre eles, na qual o valor recepcionado no princípio seja efetivamente preservado. Enquanto valor incerto em princípio fundamental, a dignidade da pessoa humana serve de parâmetro para a aplicação, interpretação e integração de todo o ordenamento jurídico, destacando assim o seu caráter instrumental. Neste sentido, vale ressaltar:

Quando a Constituição elencou um longo catálogo de direitos fundamentais e definiu os objetivos fundamentais do Estado, buscou essencialmente concretizar a dignidade da pessoa humana. Afinal, de nada adiantaria a simples menção ao princípio fundamental da dignidade da pessoa humana se a Constituição de 1988 não garantisse um núcleo básico de direitos aos cidadãos. Em suma, temos que a unidade axiológico-normativa do sistema constitucional deve ser aferida, essencialmente, a partir de uma tábua axiológica, em cujo cerne se encontra a dignidade da pessoa humana e os direitos fundamentais [...] (25)

A despeito desta abordagem, o reconhecimento da dignidade da pessoa humana pela ordem jurídico-positiva não está afirmando que a dignidade da pessoa exista apenas nas bases do Direito. Contudo, do grau de reconhecimento e proteção outorgado à dignidade por cada ordem jurídico-constitucional e pelo ordenamento jurídico pátrio e internacional, essencialmente irá depender sua efetiva realização e promoção, de tal forma que se impõe uma análise do conteúdo jurídico, ou melhor, da dimensão jurídica da dignidade no contexto da articulação constitucional pátria, "designadamente, a força jurídica que lhe foi outorgada na condição de norma fundamental" (24).

Ao finalizar estas breves considerações acerca do princípio da dignidade da pessoa humana e o direito à saúde, percebe-se que a Constituição de 1988 plasmou, a guisa de fundamento da República Federativa do Brasil como Estado Democrático de Direito, a 
dignidade da pessoa humana enquanto instrumento de subsídio para a consecução do direito à saúde, retratando o reconhecimento de que o indivíduo há de constituir o objetivo primordial da ordem jurídica. Firmado enquanto fundamental princípio - cuja função de diretriz hermenêutica lhe é irrecusável - traduz a repulsa constitucional às práticas, imputáveis aos poderes públicos ou aos particulares, que visem a expor o ser humano, enquanto tal, em posição de desigualdade perante os demais, a desconsiderá-lo como pessoa, reduzindo-o à condição de coisa, ou ainda a privá-lo dos meios necessários à sua manutenção, destacando-se aqui o Direito à Saúde.

\section{Considerações finais}

A pretensão na construção deste artigo não foi a de concluir efetivamente esta abordagem, mas apenas apresentar algumas considerações acerca de questões observadas ao longo de sua realização. Por conseguinte, sábias são as palavras de Ost quando diz: [...] não é preciso concluir. É preciso, pelo contrário, abrir o círculo: ei-lo tornado em espiral e turbilhão, circularidade em movimento como a própria vida e as ideias $[\ldots]$.

Assim é a pesquisa, não um estudo definitivo, mas sim uma forma de proporcionar questionamentos, reflexões e alternativas para produzir conhecimento sobre assuntos de direta e fundamental importância para o processo de construção e consolidação do Estado Democrático de Direito e, consequentemente, de seus relevantes princípios, efetivando, desta forma, a cidadania.

Nos dias de hoje, falar em "direito à saúde e dignidade da pessoa humana" é sinônimo de um pensamento que nos remete à ideia de implementação e busca da consolidação dos direitos das pessoas enquanto seres humanos, dignos de exercerem seus direitos, mas também de cumprirem seus deveres enquanto cidadãos pertencentes a um Estado de Direito. Afinal, ser cidadão é ter consciência de que se é "sujeito de direitos," direitos esses de cunho civis, políticos e sociais, onde encontra-se o direito à vida e consequentemente à saúde.

É desta forma que se pode contribuir para o efetivo exercício da cidadania, pois uma sociedade de cidadãos é uma sociedade de relações democráticas baseada na igualdade entre as pessoas e, sobretudo no respeito pela dignidade humana. $O$ cidadão tem de ser cônscio das suas responsabilidades enquanto parte integrante de um grande e complexo 
organismo que é a coletividade, a nação e o Estado, onde todos são responsáveis pela concretização de direitos. É desta forma que se chega ao objetivo final e coletivo - a justiça em seu sentido mais amplo, ou seja, o bem comum.

Finalizando, pode-se ratificar a impossibilidade de se dissociarem os vetores da dignidade humana e do direito à saúde, surgindo desta forma um sólido instrumento de efetividade e exigibilidade dos direitos fundamentais, em direção à positivação do exercício da cidadania, representada não só pela concretização de direitos, mas também pela perspectiva de afirmar princípios como o da solidariedade e da igualdade, posto que 0 direito à saúde é direito à vida, o bem máximo da humanidade. Logo, os pressupostos do princípio da dignidade da pessoa humana, enquanto fator legitimador do direito à saúde, afirmam-se como um importante aliado da coletividade na busca pela concretização dos tão idealizados direitos fundamentais.

\section{Referências}

1.Dallari, SG. A saúde do brasileiro. São Paulo Paulo: Editora Moderna, 1987.

2.Bompiani, A. Considerazioni in merito alla politica di sicurezza sociale nel settore dell'assistenza e della sanità. Rimini: Maggioli, 1996.

3.Sobrinho, LLP. Direito à saúde, evolução e positivação no constitucionalismo brasileiro. 2001. 195 f. Dissertação (Programa de Pós-Graduação em Direito - Mestrado) Universidade de Santa Cruz do Sul, Santa Cruz do Sul, 2001.

4.Morais, JLB Do direito social aos interesses transindividuais. Porto Alegre: Livraria do advogado, 1997.

(5) Uerlinguer, C. A doença. São Paulo: Hucitec, 1998.

(6) Fiorio, C. Libertà personale e diritto alla salute. Padova: CEDAM, 2002.

(7) Dias, HP. A responsabilidade pela saúde - Aspectos jurídicos. Rio de Janeiro: Fiocruz, 1995.

(8) Silva, JA Curso de direito constitucional positivo. 20. ed. São Paulo: Malheiros Editores, 2002.

(9) Sobrinho, LLP. O direito sanitário: uma perspectiva democrática deliberativa. Revista Justiça do Direito, Passo Fundo, n. 1, p. 28-36, 2003. 
(10) Brasil. Constituição (1988). Constituição da República Federativa do Brasil. Brasília, DF: Senado Federal, 1988.

(11) Carvalho, Gl; Santos, L. Sistema único de saúde. Comentários à Lei Orgânica da Saúde 8.080 de 1990 e 8.142 de 1990. 2. ed. São Paulo: Hucitec, 1995.

(12) Moraes, A. Direito constitucional. 10. ed. São Paulo: Atlas S. A., 2002.

(13) Ramos, JS. Serviços de saúde prestados pela iniciativa privada e o contrato de seguro-saúde. Revista dos Tribunais, São Paulo, n. 12, p. 281-290, jul./set. 1995.

(14) Delduque, MC. A Mediação Sanitária como novo paradigma alternativo à judicialização das políticas de saúde no Brasil. In: Conselho nacional de secretários de saúde - CONASS. Para Entender a Gestão do SUS. Brasília: 2015.

(15) Dias, JC. O sistema penitenciário brasileiro: panorama geral. Revista do Centro de Estudos Judiciários - CEJ, Brasília, n. 15, p. 8-11, set./dez. 2001.

(16) Vargas, GOP. Direito e saúde: formas de controle social sobre serviços e ações de saúde. Revista do Curso de Direito da Universidade Federal de Uberlândia, Uberlândia, n. 1/2, p. 47-60, dez. 1997.

(17) Dallari, DA. Viver em sociedade. São Paulo: Moderna Ltda, 1985.

(18) Neto, ER. Saúde - Promessas e limites da Constituição. Rio de Janeiro: Fiocruz, 2003.

(19) Podval, MLO. A tutela específica em face do poder público. Políticas públicas de saúde e o princípio constitucional da separação dos poderes. Revista da Procuradoria Geral do Estado de São Paulo, São Paulo, n. especial, p. 167-194, jan./dez. 2003.

(20) Santos, BS. A crítica da razão indolente: contra o desperdício da experiência. 3. ed. São Paulo: Cortez, 2001.

(21) Júnior, EPN. O direito brasileiro e o princípio da dignidade da pessoa humana. Disponível em: < http://www.jfrn.gov.br/docs/doutrina93.doc>. Acesso em: 10 out. 2016.

(22) Spitzcovsky, C. O direito à vida e as obrigações do Estado em matéria de saúde. Disponível em: <http://jus2.uol.com.br/doutrina/texto.asp?id=8382>. Acesso em: 13 out. 2016.

(23) Neto, AAA. Dano existencial - a tutela da dignidade da pessoa humana. Disponível em: < http://www.apmp.com.br/juridico/artigos/docs/2005/dano existencial .doc>. Acesso em: 13 out. 2016.

(24) Sarlet, IW. Dignidade da pessoa humana e direitos fundamentais na Constituição Federal de 1988. Porto Alegre: Livraria do Advogado, 2001. 
Cadernos Ibero-Americanos

de Direito Sanitário

Cuadernos Iberomericanos

de Derecho Sanitario

(25) Martins, FJB. Dignidade da pessoa humana - princípio constitucional fundamental. Curitiba: Jaruá Editora, 2003.

Recebido em: 19.3.2017

Aprovado em: 19.6.2017

Como citar este artigo:

Martini SR, Sturza JM. A dignidade humana enquanto princípio de proteção e garantia dos direitos fundamentais sociais: direito à saúde. Revista Cadernos Ibero-Americanos de Direito Sanitário. 2017 jan./mar, 6(2):25-41. 